\title{
AUTONOMÍA PERSONAL Y REFLEXIÓN: UN ANÁLISIS DE LAS IDEAS DE HARRY FRANKFURT Y GERALD DWORKIN
}

\section{PERSONAL AUTONOMY AND REFLECTION: AN ANALYSIS OF THE IDEAS OF HARRY FRANKFURT AND GERALD DWORKIN}

\author{
JUAN FRANCISCO IOSA \\ Profesor de Filosofia del Derecho de la Universidad Nacional de Córdoba y profesor de Teoría de la Argumentación \\ Jurídica. Córdoba, Argentina. \\ juanfiosa@gmail.com
}

\section{RESUMEN}

Argumento en contra de una concepción de la autonomía personal centrada en la identificación entre deseos de primer y segundo orden -aquí denominada concepción empírica de las metapreferencias - y a favor de una concepción con eje en la idea de reflexión - la concepción normativa de las metapreferencias. Ambas, sostengo, son lecturas posibles de las tesis que respecto de la autonomía personal sostienen Harry Frankfurt y Gerald Dworkin. Por su vinculación con la concepción empírica rechazo un liberalismo radical tal que implique la obligación del estado de respetar cualquier plan de vida con que el agente se identifique. En virtud de su conexión con la concepción normativa sugiero, en cambio, la viabilidad de un perfeccionismo liberal donde el valor de la autonomía personal justifique la intervención estatal en los planes de vida que la amenazan.

Palabras clave: autonomía personal; Gerald Dworkin; Harry Frankfurt; liberalismo político; perfeccionismo liberal.

\begin{abstract}
I argue against a conception of personal autonomy focused on identification between desires of first and second order - here called empirical conception of second order preferences - and for a conception centered on the idea of reflection - the normative conception of second order preferences. Both, I assert, are possible readings of the theses about personal autonomy asserted by Harry Frankfurt and Gerald Dworkin. Because of its link with the empirical conception I reject here a radical liberalism involving the state's obligation to respect any self-regarding life plan preferred by the agent. By virtue of its connection to the normative conception I suggest, on the contrary, the feasibility of a liberal perfectionism such that the value of personal autonomy justifies state intervention in the life plans that jeopardize it.
\end{abstract}

Keywords: Personal Autonomy; Gerald Dworkin; Harry Frankfurt; political liberalism; liberal perfectionism. 


\section{SUMARIO}

INTRODUCCIÓN; 1 LA IDEA DE AUTONOMÍA PERSONAL EN HARRY FRANKFURT; 2 LA IDEA DE AUTONOMÍA PERSONAL EN GERALD DWORKIN; 2.1 Tesis básicas; 2.2 Autenticidad; 2.3 Independencia procesal; 2.4 Independencia sustantiva; 2.5 Crítica; 2.6 Crítica de la versión empírica de la autonomía y determinación de las consecuencias de la versión normativa; BIBLIOGRAFÍA.

"Así pues, hizo al hombre de una forma indefinida y, colocado en el centro del mundo, le habló de esta manera: "No te dimos ningún puesto fijo, ni una faz propia, ni un oficio peculiar, joh Adán!, para que el puesto, la imagen y los empleos que desees para $t i$, esos los tengas y poseas por tu propia decisión y elección. Para los demás, una naturaleza contraída dentro de ciertas leyes que les hemos prescripto. Tú, no sometido a cauces, algunos angostos, te la definirás según tu arbitrio al que te entregué. Te coloqué en el centro del mundo, para que volvieras más cómodamente la vista a tu alrededor y miraras todo lo que hay en este mundo. Ni celeste ni terrestre te hicimos, ni mortal ni inmortal, para que tú mismo, como modelador y escultor de ti mismo, más a tu gusto y honra, te forjes la forma que prefieras para ti. Podrás degenerar a lo inferior, con los brutos; podrás realzarte a la par que las cosas divinas, por tu misma decisión. ¡Oh sin par generosidad de Dios Padre, altísima y admirable dicha del hombre! Al que le fue dado tener lo que desea, ser lo que quisiere... iQuien no admirará a este camaleón!”

Gianfrancesco Pico dela Mirándola. De Hominis Dignitate $(1496)^{1}$

\footnotetext{
${ }^{1}$ G. Pico dela Mirandola, De la Dignidad del Hombre, Editora Nacional, Madrid, [1496]1984. p. 05. Lo atinente de esta cita como muestra del espíritu de la concepción de la autonomía defendida por Frankfurt y Dworkin, puede ser legítimamente puesta en duda si es contextualizada y leída dentro de una matriz historicista de pensamiento. Así Pico, tras la cita que coloqué arriba, continúa diciendo esto: "Los brutos, nada más nacidos, ya traen consigo (como dice Lulio) del vientre de su madre lo que han de poseer. Los espíritus superiores, desde el comienzo, o poco después ya fueron lo que han de ser por eternidades sin término. Al hombre, en su nacimiento, le infundió el Padre toda suerte de semillas, gérmenes de todo género de vida. Lo que cada cual cultivare, aquello florecerá y dará su fruto dentro de él. Si lo vegetal, se hará planta; si lo sensual, se embrutecerá; si lo racional, se convertirá en un viviente celestial; si lo intelectual, en un ángel y en un hijo de Dios. ...porque a la planta no la hace la corteza, sino su naturaleza obtusa e insensible, ni a los jumentos su pellejo, sino su alma de bestia y sensual, ni al cielo el cuerpo redondo, sino la recta razón, ni el ángel lo es por no tener cuerpo, sino por su inteligencia espiritual. Así si vieres a uno entregado a su vientre, arrastrándose por el suelo, es una planta, no es un hombre lo que ves; si vieres a alguien enceguecido, como otra Calipso, con vanas fantasmagorías y embadurnado en el halago cosquilloso de los sentidos, esclavo de ellos, bruto es y no hombre lo que ves; si a un filósofo discerniéndolo todo a la luz de la recta razón, a este venerarás, animal celeste es, no terreno; si a un puro contemplativo olvidado del cuerpo, recluido en las intimidades del espíritu, ese no es un animal, terrestre ni celeste, es ese un superior numen revestido de carne humana... 'Dioses sois todos e hijos del Altísimo' y que por usar mal de la benevolencia del Padre, no vayamos a convertir en perniciosa la saludable opción libre que nos otorgó." En Pico entonces el modo en que el hombre usa su capacidad de decidir por sí mismo lo ubica dentro de un orden que le excede, dentro de un cosmos ordenado jerárquicamente. Cuando, un poco más adelante, la creencia en ese orden desaparezca o sea fuertemente puesta en duda,
} 


\section{INTRODUCCIÓN}

La idea central detrás de la noción de autonomía personal es la de un sujeto "guiado por consideraciones, deseos, condiciones y características que no le son impuestas externamente, sino que son parte de lo que puede considerar... como (su) propio y auténtico

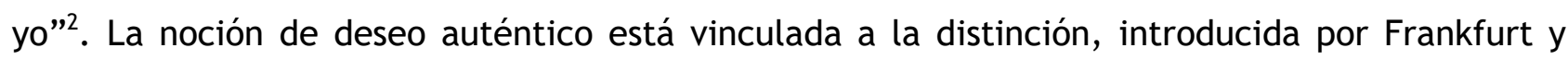
Dworkin, entre deseos de primer y segundo orden. Un deseo autentico es, entonces, aquel con el que el yo se identifica, ie, un deseo que el agente quiere (según un deseo de segundo orden) tener. Así, puedo tener el deseo de primer orden de fumar y el deseo de segundo orden de no ser un fumador, ie, desear no desear fumar. Ahora bien, no se trata sólo de que yo hoy puedo identificarme o no con un deseo actual. También puedo identificarme o rechazar mis deseos e intereses (ie, mis deseos a largo plazo) futuros. En tanto la persona puede definirse, al menos en parte, como un haz de deseos e intereses proyectados en el tiempo, podemos considerar la autonomía personal como la capacidad de considerar y proyectar qué clase de persona se quiere ser, ie, la capacidad de elegir por uno mismo el propio plan de vida ${ }^{3}$. Las personas gozan de autonomía personal si eligen o pueden elegir su propio plan de vida.

Es posible entender la autonomía personal meramente en términos de identificación entre deseos de primer y segundo orden: soy autónomo cuando tengo los deseos (de primer orden) que deseo (en el segundo orden) tener. Bien puede que esto sea todo lo que Frankfurt y Dworkin requieren para predicar autonomía personal. De hecho intentaré mostrar que ésta es una lectura posible de sus tesis. Pero entonces, argumentaré, no parece que haya lugar para la idea de reflexión ni que la formulación de deseos de segundo orden se deba a ella: que haya coincidencia o no entre nuestros deseos de diverso orden será un hecho que nos sucede, no una

sólo quedarán las preferencias. Desaparecerá la creencia en la existencia de lo que WiLLIAMs llamó 'razones externas' para quedar sólo las 'razones internas'. De hecho el pasaje citado en el cuerpo del texto es usado habitualmente para destacar el vínculo entre las ideas de autonomía personal y de plan de vida, i.e. como señalando el origen, en el renacimiento humanista, de una nueva concepción del hombre como un ser que se hace a sí mismo a partir de criterios inmanentes: “...no es sólo que hoy pueda yo prever un deseo o un interés de mi futuro yo y obrar en consecuencia para satisfacerlo, es que puedo ver y considerar qué clase de persona quiero ser y proceder entonces a construir paso a paso esa clase de persona." LAPORTA, F, 2007: El Imperio de la Ley, Trotta, Madrid, p. 31.

2 CHRISTMAN, J, 2011: "Autonomy in Moral and Political Philosophy", The Stanford Encyclopedia of Philosophy, Edward N. Zalta (ed.), disponible on line en <http://plato.stanford.edu/archives/spr2011/entries/autonomy-moral/> p. 02.

${ }^{3}$ LAPORTA, F, 2007: El Imperio de la Ley, Trotta, Madrid. p. 31-32. 
AUTONOMÍA PERSONAL Y REFLEXIÓN: UN ANÁLISIS DE LAS IDEAS DE HARRY FRANKFURT Y GERALD DWORKIN

JUAN FRANCISCO IOSA

situación producto de una toma de conciencia sobre la naturaleza de nuestros deseos. Llamémosla entonces concepción empírica de las metapreferencias.

En consonancia con estas ideas, la autonomía personal suele pensarse como una concepción formal e inmanente del valor: son valiosos y respetables los planes de vida de las personas en tanto éstas los hayan elegido libremente, ie, se identifiquen con ellos, independientemente de cuál sea su contenido. De aquí el carácter radicalmente antiperfeccionista de las construcciones basadas en esta concepción de la autonomía personal, construcciones que prescriben que el estado no debe interferir en la elección de planes de vida por parte de los individuos, que debe, por el contrario, limitarse a diseñar instituciones que faciliten la persecución individual de esos planes y, en todo caso, impedir la interferencia mutua en el curso de tal persecución ${ }^{4}$. De ser éste el caso, la autonomía personal podría pensarse como una teoría equivalente en peso normativo a la autonomía moral, como una teoría de la fuente de la normatividad: el valor de los planes de vida dependería meramente de que los hayamos elegido, de que nos identifiquemos con ellos, independientemente de su contenido y del modo en que dicha elección o identificación haya tenido lugar ${ }^{5}$.

En contra de esta lectura posible de la idea de autonomía personal en las teorías de Frankfurt y Dworkin, la concepción normativa de las metapreferencias concibe a los deseos de segundo orden como producto de la reflexión. Ahora bien, si aceptamos que no se puede concebir la idea de autonomía personal sin acudir a la idea de reflexión entonces cabe preguntarnos sobre qué versará esta reflexión. Y todo parece indicar que lo que buscará determinar es qué tan deseables son nuestros deseos. No parece haber ningún otro candidato a mano como objeto de la reflexión. Pero, a su vez, no parece posible reflexionar sobre la deseabilidad de nuestros deseos sin contar con criterios con los cuales evaluarlos. Si aceptamos que esos criterios son necesarios entonces podemos preguntarnos cuál es su fuente. Si no son subjetivos (recordemos que las preferencias son el objeto de la evaluación y en esta lectura las metapreferencias son el producto de la reflexión por lo que no pueden funcionar como criterios ex ante) y si no nos vienen dados en virtud de la existencia de un orden normativo independiente (iusnaturalismo, realismo moral) es de esperar que el único lugar de donde

\footnotetext{
${ }^{4}$ Al respecto ver NINO, C, 2007: Ética y Derechos Humanos, Astrea, Buenos Aires. p. 204-205.

${ }^{5}$ De hecho, uno de los modos de pensar la autonomía personal es concebirla justamente como aquello que queda cuando anulamos el problema de un orden moral trascendente a la persona, o cuando, habiendo anulado ese orden, también descartamos de la noción de autonomía moral cualquier vestigio de realismo. Si no hay criterios superiores a los deseos o actos de elección de la persona, no queda sino estratificar estos deseos y actos de modo de contar con criterios inmanentes.
} 
AUTONOMÍA PERSONAL Y REFLEXIÓN: UN ANÁLISIS DE LAS IDEAS DE HARRY FRANKFURT Y GERALD DWORKIN

JUAN FRANCISCO IOSA

puedan emanar sea nuestra autonomía moral. Pareciera entonces que la noción de autonomía personal es normativamente dependiente de la de autonomía moral. Ahora bien, si la capacidad de reflexión es central a la hora de predicar autonomía personal de un individuo, entonces el estado deberá adoptar políticas conducentes tanto a evitar el menoscabo de esta capacidad como a promover su desarrollo. Al respecto parece que tendrá que tener en cuenta el resultado no solo de las acciones ajenas sino también de las del propio agente en vistas de cuya autonomía se adoptan las políticas en cuestión. Esto sugiere que la teoría política que se sigue a partir de una adecuada comprensión del concepto de autonomía personal (en los términos de la concepción normativa de las metapreferencias) no es el liberalismo radical sino el perfeccionismo liberal en el sentido sugerido por Joseph Raz ${ }^{6}$. Para verificar si éste es el caso revisemos las teorías de la autonomía personal en cuestión.

\section{LA IDEA DE AUTONOMÍA PERSONAL EN HARRY FRANKFURT}

En Freedom of the will and the concept of a person ${ }^{7}$ Frankfurt sostiene que así como la afirmación de que una persona tiene libertad de acción significa que esa persona es libre de hacer lo que desea hacer, la afirmación de que una persona goza de autonomía (libertad de la voluntad en su terminología) significa que esa persona es libre de desear lo que desea desear. Para hacer inteligible esta afirmación es necesario desarrollar mínimamente su modelo jerárquico de la autonomía ${ }^{8}$.

La noción de autonomía en Frankfurt está ligada a sus investigaciones acerca del concepto de persona:

Parece ser característico de los seres humanos el que sean capaces de formar lo que llamaré "deseos de segundo orden" ... Además de querer y elegir y estar motivados para hacer esto o aquello, los hombres también pueden querer tener (o no tener) ciertos deseos y motivaciones. Ellos son capaces de querer ser diferentes, en sus preferencias y propósitos, de lo que son. Muchos animales parecen tener la capacidad de lo que llamaré "deseos de primer orden"... que son simplemente deseos de hacer o no una cosa u otra. Ningún animal que no sea el

\footnotetext{
${ }^{6}$ RAZ, J., 1986: The Morality of Freedom, Clarendon Press, Oxford.

${ }^{7}$ FRANKFURT, H, 1989: "Freedom of the Will and the Concept of a Person", en J, Christman (Ed.), The Inner Citadel, Essays on Individual Autonomy, Oxford University Press, Oxford, (de donde se cita). Originalmente el artículo salió en Journal of Philosophy 68, 1971.

${ }^{8}$ LOS modelos DE FRANKFURT y DWORKIN han sido denominados 'jerárquicos' en virtud de que afirman que la corrección del predicado 'autónoma' respecto de una persona depende de la relación entre sus diversos niveles de preferencias.
} 
AUTONOMÍA PERSONAL Y REFLEXIÓN: UN ANÁLISIS DE LAS IDEAS DE HARRY FRANKFURT Y GERALD DWORKIN

JUAN FRANCISCO IOSA

hombre, sin embargo, parece tener la capacidad de autoevaluación reflexiva que se manifiesta en la formulación de deseos de segundo orden. ${ }^{9}$

Comencemos por destacar una característica importante del planteo de Frankfurt. Los deseos de segundo orden se postulan como un criterio inmanente para juzgar (en algún sentido, aún por explicitar, de esta polisémica palabra) los deseos de primer orden. Ahora bien, estos deseos de segundo orden pueden ser pensados de dos modos:

En primer lugar podemos pensar estos deseos como un dato, esto es, como un hecho (explicable causalmente) anterior a la reflexión. Bajo esta idea la reflexión consistiría en usar este hecho empírico como criterio de evaluación de los deseos de primer orden. Llamemos a esta 'concepción empírica de las metapreferencias.' Aún quedaría por explicar cómo un hecho empírico, un deseo, sea del orden que sea, puede ser utilizado como criterio de evaluación. En principio, si los deseos son hechos, entre ellos pueden establecerse meras relaciones causales. En todo caso, más que afirmar que con estas metapreferencias evaluamos nuestras preferencias, parece más apropiado decir que estas metapreferencias expresan una actitud hacia nuestras preferencias de nivel inferior. Aceptamos algunas y rechazamos otras. "Juzgar", bajo esta concepción equivaldrá a “aceptar”, “identificarse”, o “tener una actitud positiva”.

En segundo lugar, podemos entender que los deseos de segundo orden son el producto de la reflexión crítica. Tal como lo indica la última frase de la cita, ésta parece ser la opción de FRANKFURT. A su entender los deseos de segundo orden son generados por la reflexión. Llamemos a esta 'concepción normativa de las metapreferencias' Tiene, como es de esperar, sus propios problemas.

Advirtamos, por un lado, que la reflexión tiene por objeto creencias y sólo indirectamente deseos, en tanto estos son el contenido de determinadas creencias. Una reflexión típica dentro de este modelo correría del siguiente modo: tengo el deseo [de primer orden] de $\mathrm{x} 0$, mejor dicho, creo que tengo el deseo de $\mathrm{x}, \mathrm{y}$ me pregunto si este deseo que creo tener es un deseo deseable, ie, digno de tenerse. De responder afirmativamente ahora tendré dos metacreencias, por un lado la creencia de que el deseo de primer orden es deseable, un deseo aprobado de acuerdo al criterio de evaluación utilizado. Por otro lado tendré la creencia más general de que tener determinado tipo de deseos es deseable. Es decir, tendré una creencia relativa a qué deseos de primer orden quiero tener o, en términos más generales, una creencia

\footnotetext{
${ }^{9}$ FRANKFURT, H, 1989: "Freedom of the Will and the Concept of a Person", en J, Christman (Ed.), The Inner Citadel, Essays on Individual Autonomy, Oxford University Press, Oxford, (de donde se cita). Originalmente el artículo salió en Journal of Philosophy 68, 1971. p. 64.
} 
AUTONOMÍA PERSONAL Y REFLEXIÓN: UN ANÁLISIS DE LAS IDEAS DE HARRY FRANKFURT Y GERALD DWORKIN

JUAN FRANCISCO IOSA

relativa a qué tipo de persona quiero ser (creo que quiero ser el tipo de persona que tiene los deseos del tipo $X$ pero no los deseos de tipo $Y$ ). Ahora bien, Frankfurt afirma además que de la reflexión surgen nuevos deseos de segundo orden. Si esto es así entonces la tesis de Frankfurt supone algún tipo de internalismo de las razones, esto es, la idea de que del mero hecho de creer que es deseable -que tengo razones para- tener determinado deseo de segundo orden, surge ese deseo ${ }^{10}$. Si uno asume una distinción tajante entre deseos y creencias, el internalismo es problemático.

Por otra parte, si entendemos que las metapreferencias surgen sólo después de la reflexión y en tanto que, bajo este concepción, con lo único con que, por principio, contamos a la hora de la reflexión es con nuestras creencias relativas a nuestros deseos de primer orden (creencias que son la materia de la reflexión, ie, “creo que deseo x"), resulta que no tenemos ningún criterio inmanente que permita la reflexión. Si las metapreferencias son generadas por la reflexión, ie, son adoptadas libremente por el agente, si no son producto de relaciones causales, parece que su adopción supone algún criterio, que esta vez no puede ser inmanente ni fáctico, que nos permita decidir qué metapreferencias es deseable tener. La concepción normativa de las metapreferencias parece suponer algún criterio objetivo, ie, la existencia de razones objetivas y externas (aunque no sean más que procesales), como condición de posibilidad de la generación de metapreferencias. Si la idea era ofrecer un análisis en términos meramente internos, esto no parece poder lograrse por estos medios.

Vale tener en mente la distinción realizada porque nos será útil en el resto del análisis, particularmente al evaluar la teoría de Dworkin. Volvamos ahora a Frankfurt. A su entender los deseos de segundo orden pueden ser de dos tipos. Alguien puede tener un deseo de tener determinado deseo (sin implicar que desea que este deseo sea el efectivo, el que lo mueva actuar, sino un deseo más entre el conjunto de deseos de primer orden); o puede desear tener determinado deseo y desear que este deseo sea su voluntad. Para Frankfurt la noción de voluntad se refiere a un deseo efectivo, uno que mueve a la acción.

Frankfurt está interesado en esta última subclase de deseos de segundo orden a la que llama voliciones de segundo orden. Afirma que es el tener estas voliciones de segundo orden, y no el tener deseos de segundo orden en general, lo que es esencial para ser una persona. Sólo en virtud de que tenemos voliciones de segundo orden es que somos capaces, a su entender, tanto

\footnotetext{
10 Para la discusión entre internalismo y externalismo, entendida esta distinción como referida a la discusión relativa al vínculo entre razones y motivos, véase: SMITH, M, 1994: The Moral Problem, Blackwell Publishers, Oxford.
} 
de gozar como de carecer de libertad de la voluntad. Así FRANKFURT construye el concepto de persona como el de un tipo de entidad para la cual la libertad de la voluntad puede ser un problema $^{11}$. A esta última idea se refiere en los siguientes términos:

Es al lograr conformar su voluntad a sus voliciones de segundo orden... que la persona ejerce libertad de la voluntad. Y es en la discrepancia entre su voluntad y sus voliciones de segundo orden, o en su conciencia de que la coincidencia no es un logro suyo sino solamente una feliz coincidencia, que la persona que no tiene esta libertad siente su falta. ${ }^{12}$

Cuando una persona tiene determinada voluntad conforme con sus voliciones de segundo orden podemos decir que esa persona se identifica con su voluntad o con sus deseos de primer orden. Cuando una persona logra moldear su voluntad gracias a la fuerza de sus voliciones de segundo orden podemos decir, según este modelo, que es autónoma. El modelo de Frankfurt parece entonces estar vinculado a una concepción tanto normativa como motivacional de las metapreferencias. Éstas no sólo serían relevantes a la hora de evaluar las preferencias. Por el contrario, son útiles también por su capacidad performativa. Expresan una fuerza motivacional de orden superior que permite modificar o modelar las motivaciones de orden inferior. Sin duda puede ser problemática la atribución conjunta de normatividad y carácter motivacional a las metapreferencias, tal como es problemática esa atribución a la noción misma de deber. ${ }^{13}$ Pero el análisis de esa tensión no se puede emprender aquí.

\section{LA IDEA DE AUTONOMÍA PERSONAL EN GERALD DWORKIN}

\subsection{Tesis básicas}

Las reflexiones de G. Dworkin siguen un camino muy similar aunque su argumentación es más amplia y a mi gusto menos precisa que la de Frankfurt. La falta de precisión se debe a que incorpora elementos en tensión. De aquí que reconstruir su pensamiento no sea tarea sencilla.

\footnotetext{
${ }^{11}$ FRANKFURT, H, 1989: "Freedom of the Will and the Concept of a Person", en J, Christman (Ed.), The Inner Citadel, Essays on Individual Autonomy, Oxford University Press, Oxford, (de donde se cita). Originalmente el artículo salió en Journal of Philosophy 68, 1971. p. 69.

12 FRANKFURT, H, 1989: "Freedom of the Will and the Concept of a Person", en J, Christman (Ed.), The Inner Citadel, Essays on Individual Autonomy, Oxford University Press, Oxford, (de donde se cita). Originalmente el artículo salió en Journal of Philosophy 68, 1971. p. 70-71.

${ }^{13}$ Al respecto véase SMITH, M, 1994: The Moral Problem, Blackwell Publishers, Oxford.
} 
En Autonomy and Behavior Control ${ }^{14}$, y luego de destacar que todo concepto de autonomía debe explicitar las condiciones bajo las cuales podemos decir de nosotros mismos que nos autogobernamos, Dworkin comienza construyendo su concepción por oposición a la de KANT (a su versión de KANT). Según Dworkin la noción kantiana de autonomía se refiere a principios cuyo contenido no está determinado ni por las contingentes circunstancias de la socialización humana ni por peculiaridades biológicas de la especie ni por las contingentes inclinaciones del agente sino que son autolegislados.

Me interesa destacar tres observaciones de Dworkin relativas al concepto kantiano de autonomía. La primera es que, según Dworkin, la autonomía moral kantiana (y en general la idea de autonomía moral), como relativa a reglas o principios, es un caso especial de la idea más general de autonomía en que estamos interesados cuando pretendemos establecer principios regulativos de la interferencia legítima (la interferencia de la autoridad, por ejemplo) en el comportamiento ajeno.

Aquellos preocupados por si los fármacos interfieren con la autonomía no están preocupados por las reglas o mandatos o principios que el agente está obedeciendo o adoptando. Están interesados por una relación más general entre el comportamiento de las personas y su estructura motivacional. Es cierto, tienen interés en lo que explica el comportamiento específico de las personas, pero esa explicación puede ( $\mathrm{y}$ suele) referirse a un conjunto mucho más amplio de elementos mentales -creencias, quereres, decisiones, juicios, deseos, emociones, motivos, hábitos, compulsiones, y cosas semejantes. ${ }^{15}$

Si lo que nos preocupa es qué situaciones interfieren con la autonomía de las personas no nos podemos quedar, según Dworkin, estancados en el nivel de las reglas y valores morales, porque muchos otros factores son relevantes. Dworkin entiende entonces que la relación entre autonomía personal y autonomía moral es una de género - especie, siendo la primera la clase más amplia.

La segunda crítica al concepto kantiano de autonomía no se limita a indicar que éste es a un caso especial de autonomía, sino que directamente la califica como inadecuada. La idea kantiana de autonomía llevaría a paradojas y dificultades que la volverían imposible. A su entender en la idea kantiana de autonomía moral hay una tensión irresoluble entre intuiciones voluntaristas e intuiciones racionalistas.

\footnotetext{
${ }^{14}$ DWORKIN, G, 1976: “Autonomy and Behavior Control”, The Hastings Center Report, Vol. 6, № 1.

${ }^{15}$ DWORKIN, G, 1976: “Autonomy and Behavior Control”, The Hastings Center Report, Vol. 6, № 1. p. 24.
} 
AUTONOMÍA PERSONAL Y REFLEXIÓN: UN ANÁLISIS DE LAS IDEAS DE HARRY FRANKFURT Y GERALD DWORKIN

La autonomía, en esta concepción, exige que el agente elija sus principios morales independientemente de restricciones externas. Pero para muchos filósofos morales los principios de la moral son tales que su corrección o verdad es independiente de si se los elige o no. Así que tenemos un conflicto entre estar sujeto a las limitaciones del conjunto correcto de principios y la idea de elegir cualquier cosa que el sujeto decida. ${ }^{16}$

Por último, y como sobre este punto ha de hacer descansar su argumentación, me interesa resaltar la dificultad principal que DWORKIN encuentra en el concepto de autonomía kantiano:

Todos sabemos que las personas tienen una historia. Se desarrollan social y psicológicamente en un entorno dado con un conjunto dado de dotaciones biológicas. Maduran lentamente y están muy influenciados por sus padres, hermanos, compañeros y cultura. ¿Qué sentido tiene hablar de sus convicciones, motivaciones, principios, y así sucesivamente como "auto-elegidos"? Esto presupone una noción del yo como aislado de las influencias recién enumeradas $y$, lo que es casi tan absurdo, que el ser que toma decisiones lo hace arbitrariamente. ${ }^{17}$

Por estas razones es que DWORKIN nos invita a aceptar el hecho de que en la mayoría de los casos no se puede decir que hayamos adoptado o elegido nuestras creencias, deseos, o valores. De aquí se sigue una importante consecuencia respecto de la noción de autonomía:

No se puede localizar la autonomía en el nivel de las consideraciones de primer orden sino en las consideraciones de segundo orden. Si el hombre autónomo no puede adoptar sus motivaciones de cero, todavía puede juzgarlas después del hecho. El individuo autónomo es capaz de dar un paso atrás y formular una actitud hacia los factores que influyen en su comportamento. ${ }^{18}$

Al presentar la teoría de Frankfurt distinguí dos concepciones posibles de las preferencias de segundo orden: la concepción empírica y la normativa. Ambas concepciones aceptan que existe algún tipo de relación entre las preferencias de diverso nivel. ¿Nos permite la anterior cita determinar con claridad cuál de dichas concepciones adopta Dworkin? A mi juicio la respuesta es no. Es más, tal como veremos, la tensión entre estas concepciones permea todo

\footnotetext{
${ }^{16}$ DWORKIN, G, 1976: “Autonomy and Behavior Control”, The Hastings Center Report, Vol. 6, № 1. p. 24.

La paradoja de la autonomía moral kantiana es hoy un tópico compartido en los estudios sobre el tema. Al respecto ver WOOD, A, 2008: Kantian Ethics, Cambridge University Press, N.Y, p. 106; REATH, A, 1994: "Legislating the Moral Law", Nous 28, N 4, p. 435; KAIN, P, 2004. "Self Legislation in Kant"s Moral Philosophy", Archiv für Geschichte der Philosophie, p. 264; DWORKIN, G, 1988: Theory and Practice of Autonomy, Cambridge University Press, N.Y., p. 39; IOSA, J, 2011: "La Estructura del Conflicto entre Autoridad y Autonomía", en Analisi e Diritto, Madrid, Ed. Marcial Pons, disponible on line en <http://revistas.marcialpons.es/fichaarticulo.php?id_articulo=2187> p. 54; SIEKMANN, 2012: The Logic of Autonomy, Hart Publishing, Oxford. p. 1 - 2.

${ }^{17}$ DWORKIN, G, 1976: “Autonomy and Behavior Control”, The Hastings Center Report, Vol. 6, № 1. p. 24.

${ }^{18}$ DWORKIN, G, 1976: “Autonomy and Behavior Control”, The Hastings Center Report, Vol. 6, № 1. p. 24.
} 
AUTONOMÍA PERSONAL Y REFLEXIÓN: UN ANÁLISIS DE LAS IDEAS DE HARRY FRANKFURT Y GERALD DWORKIN

JUAN FRANCISCO IOSA

su análisis y dificulta la comprensión de su teoría. El párrafo transcripto expresa claramente este problema. No está claro si DWORKIN entiende que lo importante es que el agente pueda hacer un juicio en sentido estricto, es decir una evaluación del valor de sus consideraciones de primer orden (en este caso las metapreferencias serán producto antes que condición de posibilidad de la reflexión) o si lo que importa es que el individuo autónomo sea capaz de tener una actitud de segundo orden sobre sus consideraciones (básicamente creencias y deseos) de primer orden. Por supuesto, podemos pensar que una actitud de segundo orden supone -y está determinada por- un juicio de segundo orden (un juicio, ie, una creencia, sobre qué tipo de creencias y deseos es deseable tener). 0 a la inversa, podemos reducir la idea de juicio a la idea de actitud, de preferencia. Así, mi preferencia de segundo orden (preferencia que simplemente me puede suceder tener, sin que la haya elegido ni que sea producto de una evaluación) puede servirme como criterio con el cual juzgar mis preferencias de primer orden (aquí, tal como aclarara más arriba, por 'juzgar' ha de entenderse 'prefiero o me identifico con el deseo $X$ y no con el deseo $\left.Y^{\prime}\right)$. La opción dependerá, por supuesto, de nuestras posiciones metaéticas. Pero si mantenemos separadas las ideas de actitud y de juicio, mientras la actitud de segundo orden no supone más que un estado interno del sujeto, el juicio parece suponer, tal como argumentaré más adelante, un criterio objetivo como condición de su realización ${ }^{19}$.

Debemos entonces poder determinar si la teoría de la autonomía de DWORKIN supone una concepción empírica o una normativa de las metapreferencias. Con esta idea en mente nos adentraremos en ella.

Sobre la base de la idea de que la autonomía se ubica al nivel de las consideraciones de segundo orden, DWORKIN nos ofrece la fórmula que sirve de base a su análisis: autonomía = autenticidad + independencia. Al respecto aclara:

\footnotetext{
${ }^{19}$ De todos modos el acento en que aquello sobre lo que importa tener consideraciones de segundo orden son nuestras motivaciones de primer orden, ya que éstas son las que explican nuestra acción, parece indicar que lo que a DWORKIN importa más son las actitudes, no los juicios (los juicios, entendidos ya como proposiciones, ya como razonamientos, tienen por objeto creencias). Hay párrafos que apuntan en esta dirección: "Un individuo puede identificarse o aprobar su estructura motivacional debido a una incapacidad para ver en un sentido crítico y racional su situación." DWORKIN, G, 1976: "Autonomy and Behavior Control", The Hastings Center Report, Vol. 6, № 1. p. 25. Esta cita indica que la actitud de aprobación de las motivaciones $\mathrm{o}$, en general, de todas las consideraciones de primer orden, es independiente del juicio entendido como asentimiento reflexivo. El haber juzgado y reflexionado sobre mis consideraciones de primer orden no es condición necesaria para que me identifique con ellas. Pareciera entonces que debemos entender que cuando DwORKIN dice que la persona autónoma, si bien no es la fuente de sus consideraciones de primer orden, "todavía puede juzgarlas después del hecho", por "juicio" no entiende más que la pregunta por qué actitud generan esas consideraciones.
} 
La persona autónoma es aquella que hace lo suyo propio (his own thing). Por lo tanto, necesitamos caracterizaciones de lo que es para una motivación ser suya (his), y lo que es que sea propia (own). Lo primero es lo que llamaré autenticidad, lo segundo, independência. ${ }^{20}$

\subsection{Autenticidad}

Comencemos por el análisis de la idea de autenticidad. Esta idea es prácticamente idéntica a la de identificación entre deseos de primer y segundo orden de Frankfurt. Dworkin la precisa en los siguientes términos:

Es característico de las personas el que sean capaces de reflexionar sobre sus decisiones, motivos, deseos, hábitos, y cuestiones semejantes. Al hacerlo pueden formar preferencias al respecto. Así, una persona puede no sólo tener el deseo de fumar. También puede desear tener el deseo de fumar. Puede no simplemente estar motivada por los celos o la ira. También puede desear que sus motivaciones sean diferentes (o las mismas). Una persona puede querer romper el hábito de fumar y preferir dejar de fumar porque reconoce su carácter perjudicial y ese mero reconocimiento puede ser eficaz en el cambio de su comportamiento. Pero si ve esa ruta causal cerrada puede, considerando todas las cosas, preferir la introducción de una estructura causal tal que lo lleve a tener náuseas por el sabor o el olor del tabaco. Aun si en esta situación su comportamiento no está bajo su control voluntario, ella puede desear estar motivada de esta manera con el fin de dejar de fumar. Cuando esto es así, la persona considera que estas influencias causales son 'suyas'. La parte suya que quiere dejar de fumar es reconocida como su verdadero yo, aquel cuyos deseos quiere ver realizados. ${ }^{21}$

La noción de autenticidad es entonces relativa a la coincidencia o identificación entre mis preferencias de segundo orden y mis deseos (o en general las causas de mis acciones) de primer orden. Si mi comportamiento se condice con mis preferencias de mayor nivel, puede decirse que soy auténtico, o que mi acción es auténtica. Soy auténtico si tengo el tipo de deseos (o causas) que quiero tener y si actúo en base a esos deseos.

El análisis de la acción moral corre por líneas paralelas. Para DWORKIN si alguien se identifica con los principios que tiene entonces, sin importar cómo fueron originariamente adquiridos, esos principios son suyos ${ }^{22}$.

DWORKIN concluye estas primeras reflexiones sobre la autenticidad con otro párrafo que vale la pena transcribir:

\footnotetext{
${ }^{20}$ DWORKIN, G, 1976: "Autonomy and Behavior Control”, The Hastings Center Report, Vol. 6, № 1. p. 24.

${ }^{21}$ DWORKIN, G, 1976: “Autonomy and Behavior Control”, The Hastings Center Report, Vol. 6, № 1. p. 24.

22 DWORKIN, G, 1976: “Autonomy and Behavior Control”, The Hastings Center Report, Vol. 6, № 1. p. 25.
} 
AUTONOMÍA PERSONAL Y REFLEXIÓN: UN ANÁLISIS DE LAS IDEAS DE HARRY FRANKFURT Y GERALD DWORKIN

JUAN FRANCISCO IOSA

Es la actitud que una persona toma hacia las influencias que lo motivan lo que determina si han de considerarse 'suyas' o no. ¿Se identifica con ellas, las asimila consigo misma, se ve a sí misma como la clase de persona que desea estar motivada en estas formas particulares? Si, por el contrario, el agente lamenta verse motivado de ciertas maneras, está alienado de esas influencias, lamenta el actuar de acuerdo con ellas, preferiría ser el tipo de persona que está motivada de diferentes maneras, entonces esas influencias, aunque pueden ser causalmente eficaces, no son vistas como 'suyas'. ${ }^{23}$

Pensemos esta idea en el marco de la distinción propuesta entre una concepción empírica y una concepción normativa de las metapreferencias. Con esa idea en mente advertimos inmediatamente una ambigüedad en la presentación de la idea de autenticidad en DWORKIN. Elucidarla será de suma utilidad a la hora de criticar su pensamiento. No está claro si basta con que haya identificación o coincidencia entre las preferencias de segundo orden y sus deseos o creencias de primer orden, esto es, si basta con que tenga una actitud positiva hacia sus deseos o creencias (morales) o si además hace falta que esta actitud sea el fruto de un juicio, de una reflexión que partiendo de los deseos y creencias actuales del agente se pregunte qué tipo de deseos y creencias vale la pena tener. A pesar de las numerosas referencias a la reflexión, párrafos como el recién citado, o la afirmación de que alguien puede identificarse con sus deseos de primer orden en razón de que carece de capacidad de reflexionar sobre los mismos, indican que lo único importante es que la actitud expresada en la metapreferencia sea una actitud positiva. Ahora bien, como veremos, esta comprensión de la idea de autenticidad es incoherente con la postulación del requisito de independencia procesal, principio que desarrollaremos en breve.

A continuación Dworkin introduce algunas consideraciones que nos permiten distinguir su concepto de autenticidad (y de autonomía) del de libertad. Para Dworkin la libertad es la capacidad de decidir qué hacer en una situación concreta, la autonomía es la capacidad de decidir qué tipo de persona quiero $\operatorname{ser}^{24}$. Para ilustrar la distinción nos pide que pensemos en el caso del esclavo feliz: éste se identifica con su situación, la aprueba, quiere ser un esclavo. Sin embargo, si quisiera cambiarla, ello no estaría en sus manos. Esta persona no es libre, pero sí es autónoma en el esquema de DworkIN. Comparemos su caso con el del adicto contento:

¿Qué pasa con el hombre que es un adicto a las drogas, que no puede renunciar a su compulsión por la droga pero que, sin embargo, quiere estar en las garras de su compulsión? En mi opinión, este agente es autónomo. Él, como el esclavo, no

\footnotetext{
${ }^{23}$ DWORKIN, G, 1976: "Autonomy and Behavior Control”, The Hastings Center Report, Vol. 6, № 1. p. 25.

24 DWORKIN, G, 1989: "The Concept of Autonomy", en John Christman (Ed.), The Inner Citadel. Essays on Individual Autonomy, Oxford University Press, N.Y., Oxford. p. 60.
} 
es libre, ya que tomará la droga independientemente de si desea ser motivado de esta manera. Pero, importante como este hecho es, hay otro hecho que también es cierto y también es importante. El hecho de que se identifica con su adicción. $Y$ es esta identificación lo que estoy designando como autenticidad. ${ }^{25}$

\footnotetext{
${ }^{25}$ DWORKIN, G, 1976: “Autonomy and Behavior Control”, The Hastings Center Report, Vol. 6, № 1. p. 25. Vemos que en este punto difieren FRANKFURT y DWORKIN. FRANKFURT introducía como requisito indispensable para poder predicar autonomía, un elemento que Dworkin no introduce. Según FRANKFURT era necesario que en la voluntad del agente sea moldeada por sus voliciones de segundo orden, esto es, que la identificación no sea meramente producto de una feliz coincidencia. En cambio, la idea de autenticidad parece estar definida en DWORKIN de un modo estático, ie, hay o no hay identificación entre consideraciones de primer y segundo orden; no se pretende dar cuenta de la posibilidad de que un orden modifique al otro ni hay entre ambos ordenes una preeminencia normativa. Consecuentemente DWORKIN niega que de la idea de identificación (y del concepto de autonomía) se siga que nuestras metapreferencias puedan tener una influencia causal en el comportamiento: "Nótese que no se sigue que siempre podamos cambiar nuestro comportamiento o hacer ciertos deseos eficaces en nuestras acciones. Pero eso es otro tema. ... El adicto a las drogas, que desea ser un adicto, que quiere ser la clase de persona que anhela drogas, puede no ser capaz de cambiar su comportamiento o sus deseos. Pero sus acciones expresan su visión de qué tipo de influencias quiere que lo motiven. Y él es, por lo tanto, en mi opinión, autónomo. $Y$ es precisamente porque es autónomo que puede ser considerado responsable por ser esa clase de persona." DWORKIN, G, 1989: "The Concept of Autonomy", en John Christman (Ed.), The Inner Citadel. Essays on Individual Autonomy, Oxford University Press, N.Y., Oxford. p. 60-61. Que nuestras metapreferencias puedan o no alterar nuestras preferencias y nuestras decisiones y acciones particulares es una cuestión empírica y contingente, no derivable del concepto dworkiniano de autonomía.

De esto parece seguirse que quizás sea incorrecta mi afirmación de que la idea de autonomía personal, tal como la entiende DWORKIN, está íntimamente vinculada a la idea de decisión y, particularmente, de decisión sobre el propio plan de vida. Hay un sentido obvio en que la idea de que decidimos sobre nuestras vidas es falsa. Como destaca DWORKIN, en principio no decidimos sobre el contenido de nuestros deseos de primer orden (tampoco sobre nuestras creencias, pero nadie pretende que decidamos libremente sobre ellas: están guiadas por el mundo). "Esta concepción de la autenticidad se opone a la visión existencialista tradicional con su énfasis en la elección y la decisión. Dado que nacemos dentro de sociedades en una etapa particular de desarrollo, con roles sociales dados que proporcionan un marco para la participación, con un cuerpo de conocimiento acumulado a lo largo del tiempo, con supuestos morales y de otros tipos integrados en el marco social, la noción de la decisión o elección es inverosímil como una descripción de cómo adquirimos nuestras estructuras motivacionales. Nosotros simplemente nos encontramos motivados de ciertas maneras y la noción de la elección, desde nivel cero, no tiene sentido." DWORKIN, G, 1976: "Autonomy and Behavior Control", The Hastings Center Report, Vol. 6, № 1. p. 25. Podemos sin duda aceptar que nuestros deseos de primer orden están determinados por el proceso de socialización. ¿No hay entonces, tal como parece indicar este párrafo, ningún lugar para la idea de elección? Depende, a mi juicio, de cómo entendamos la relación entre consideraciones de primer y segundo orden. Podemos, de un modo a mi entender poco plausible, considerar que la relación entre consideraciones de primer y segundo orden es completamente estática y que no hay ninguna influencia recíproca. Así puedo desear fumar ahora y desear no ser un fumador, y ninguna de estas consideraciones afectaría la otra. También podemos concebir en términos puramente causales la relación entre ambos niveles de deseos. Pero si podemos voluntariamente utilizar nuestras consideraciones de segundo orden para alterar las de primer orden, parece que hay un lugar para la idea de decisión. Si cabe pensar en la posibilidad de decidir hacer un esfuerzo para alterar los deseos de primer orden y la acción resultante de esos deseos; si puedo, por ejemplo decidir dejar de fumar y contener mis deseos al respecto porque no quiero ser un fumador, entonces parece que queda un lugar para la idea de decisión. Así parece entenderlo el mismo DwORKIN cuando, inmediatamente después del párrafo trascripto, concluye afirmando que "...siempre nos reservamos la posibilidad de dar un paso atrás y juzgar dónde estamos y dónde queremos estar." (p. 25). Si tiene sentido determinar en donde estamos y hacia dónde queremos ir, esto debe ser porque tenemos alguna posibilidad de alterar nuestra estructura motivacional. Si éste es el caso, se sigue que no todos
} 
AUTONOMÍA PERSONAL Y REFLEXIÓN: UN ANÁLISIS DE LAS IDEAS DE HARRY FRANKFURT Y GERALD DWORKIN

JUAN FRANCISCO IOSA

Pasemos ahora al análisis de la idea dworkiniana de independencia. Pues la autenticidad es, según Dworkin, condición necesaria pero no suficiente de la autonomía. "La estructura motivacional de una persona puede ser suya sin ser propia"26.

\subsection{Independencia procesal}

Lo segundo que, según Dworkin, hay que introducir es el requisito de "independencia procesal." Es una idea compleja y, a mi juicio, su postulación como requisito para predicar autonomía es incompatible con la postulación del requisito de autenticidad. De modo que me resulta muy difícil reconstruirla por un lado y criticarla por otro. Intentaré de todos modos ofrecer primero una reconstrucción fiel e inteligible dentro de lo posible. Para comenzar, notemos con DWORKIN que, respecto de un individuo en que coinciden consideraciones de primer y segundo orden, bien puede ser que

...la identificación con sus motivaciones, o la elección del tipo de persona que quiere ser, pueden ser producto de la manipulación, el engaño, la retención de información pertinente, y así sucesivamente. Pudo haber sido influido de manera decisiva por otros de una manera tal que no estamos dispuestos a pensar en ello como fruto de su propia elección. ${ }^{27}$

El primer punto a destacar es que la idea de independencia procesal es relativa al modo en que adquirimos nuestras consideraciones de segundo orden, ie, a cómo hemos llegado a identificarnos con nuestras consideraciones de primer orden, o cómo hemos llegado a aborrecerlas. Si no hubo influencias indebidas y la persona se identifica con sus preferencias, entonces es, en principio, autónoma. Si estas influencias tuvieron lugar, aun cuando se identifique, no lo es. Lo que hace falta entonces es un criterio para determinar qué influencias

nuestros deseos y consideraciones de primer orden están determinados por el proceso de socialización. Algunos deben poder surgir de (o ser alterados por) nuestras consideraciones de segundo orden acerca del tipo de personas que queremos ser y de nuestra decisión de actualizar esas consideraciones. La pregunta entonces es si debemos incluir o no dentro de la idea de autonomía la capacidad de alterar nuestras preferencias mediante nuestras metapreferencias. DWORKIN rechaza que esta capacidad sea un requisito de su noción de autenticidad y, consecuentemente, de su noción de autonomía. Por ello el adicto que se identifica con su adicción es autónomo aún cuando de no identificarse con ella no podría cambiar su situación. Si éste es el caso DWORKIN debería eliminar de sus textos sus frecuentísimas referencias a las ideas de 'elección', 'decisión' y 'elección del tipo de persona que se quiere ser'.

${ }^{26}$ DWORKIN, G, 1976: "Autonomy and Behavior Control”, The Hastings Center Report, Vol. 6, № 1. p. 25.

${ }^{27}$ DWORKIN, G, 1976: “Autonomy and Behavior Control”, The Hastings Center Report, Vol. 6, № 1. p. 25. 
AUTONOMÍA PERSONAL Y REFLEXIÓN: UN ANÁLISIS DE LAS IDEAS DE HARRY FRANKFURT Y GERALD DWORKIN

JUAN FRANCISCO IOSA

interfieren indebidamente con nuestra elección del tipo de personas que queremos ser, ie, con la formación de preferencias de segundo orden.

Pongamos el ejemplo de una mujer que, educada en un ambiente de machismo recalcitrante, adopta como suyas, ie, se identifica con las prácticas machistas que la alienan. ¿Podemos decir que a esta mujer no le ha sido respetada la independencia procesal en la formación de sus preferencias de segundo orden? Supongamos que esta mujer, a consecuencia de la socialización opresiva en que vive, quiere, decide por sí, ser el tipo de mujer que tiene 18 hijos cuya crianza está completa y únicamente a su cargo. ¿Podemos decir dentro del esquema de Dworkin, que esta decisión es suya propia (her own) ${ }^{28}$ Nuestro criterio de independencia procesal debería permitirnos contestar a esta pregunta.

Corresponde entonces precisar qué tipo de influencias sobre otros impiden que se pueda decir de sus decisiones respecto de qué tipo de persona quiere ser, ie, con qué consideraciones de primer orden se quiere identificar, que son suyas propias. Hay casos claros de influencia que no cuentan como interferencia en la independencia procesal ajena (Dworkin ejemplifica con la educación y la información, la provisión de modelos de conducta, la exigencia de pensamiento lógico y la argumentación), y casos paradigmáticos de interferencia (manipulación, engaño, hipnosis, persuasión coercitiva, influencia subliminal, -ipropaganda?- etc.). ¿Con qué criterio hemos entonces de distinguir entre aquellos modos de influencia sobre (la formación de) las preferencias de segundo orden de los demás que respetan la independencia procesal y aquellos que la violan? 0 en todo caso ¿cuál es el criterio que implícitamente usamos cuando distinguimos los casos de influencia legítima de los de influencia ilegítima? Según Dworkin la respuesta se sigue de los elementos del concepto de autonomía hasta aquí ofrecidos:

Dada la naturaleza de segundo orden de la autonomía... hay una consecuencia inmediata respecto a los tipos de métodos que es legítimo utilizar para influir en las personas: si uno valora la autonomía... los métodos que interfieren con la capacidad del individuo para reflexionar sobre sus motivaciones de primer orden no deben ser utilizados. ${ }^{29}$

No hace falta insistir demasiado en el resurgimiento de la relevancia de la reflexión como elemento constitutivo de la independencia procesal y por ende de la autonomía. Aquí

\footnotetext{
${ }^{28}$ He aquí otro punto donde se nota que para esta teoría la idea de un agente decidiendo por sí no carece enteramente de relevancia.

${ }^{29}$ DWORKIN, G, 1976: “Autonomy and Behavior Control”, The Hastings Center Report, Vol. 6, № 1. p. 26.

Esta idea resulta bastante extraña incluso dentro de una matriz internalista de pensamiento moral. De la reflexión pueden surgir creencias de segundo orden pero habrá que explicar cómo es que estas creencias producto de la reflexión pueden generar preferencias.
} 
AUTONOMÍA PERSONAL Y REFLEXIÓN: UN ANÁLISIS DE LAS IDEAS DE HARRY FRANKFURT Y GERALD DWORKIN

JUAN FRANCISCO IOSA

nuevamente parece que no basta que uno tenga una actitud positiva hacia las propias consideraciones de primer orden sino que también importa que esa actitud sea fruto de la reflexión. Las metapreferencias serían así un producto de la reflexión, ie, serían adquiridas libremente y no generadas causalmente.

\title{
2.4 Independencia sustantiva
}

Hay otro elemento que DWORKIN considera preanalíticamente vinculado a la idea de autonomía:

\begin{abstract}
Supongamos... que las identificaciones y aprobaciones sufren influencias tales que no son un obstáculo a la independencia procesal. Aun así una persona puede decidir renunciar a su independencia de pensamiento o acción porque quiere (genuinamente) ser esa clase de persona. Una persona puede desear hacer cualquier cosa que su madre, o su gobierno, le dice que haga, y hacerlo de un modo procesalmente independiente. Al renunciar a lo que yo llamo independencia sustantiva esa persona ha abandonado auténticamente algo que nos inclinamos a pensar es una parte importante de la autonomia. ${ }^{30}$
\end{abstract}

La idea de independencia sustantiva tiene que ver con la determinación de si el agente toma de hecho sus propias decisiones al momento de actuar y con si juzga por sí mismo qué ha de hacer. Es independencia de pensamiento y acción. Es 'sustantiva' porque excluye algunos planes de vida que un agente procesalmente independiente pudiera querer ${ }^{31}$. Mientras la idea de independencia procesal se situaba al nivel de las consideraciones de segundo orden (aunque debemos recordar que la idea de consideraciones de segundo orden es idéntica a la de identificación con o rechazo de consideraciones de primer orden) y preguntaba si el agente no había recibido influencias indebidas al momento de adoptarlas, la noción de independencia sustantiva parece situarse al nivel de las consideraciones de primer orden -ya que éstas son las que mueven directamente al agente a la acción- y preguntar si el agente actuó sobre la base de creencias y, particularmente, de motivos de primer orden que le son propios (pero es muy difícil

\footnotetext{
30 DWORKIN, G, 1976: “Autonomy and Behavior Control”, The Hastings Center Report, Vol. 6, № 1. p. 25.

31 En DWORKIN, G, 1989: “The Concept of Autonomy”, en John Christman (Ed.), The Inner Citadel. Essays on Individual Autonomy, Oxford University Press, N.Y., Oxford. p. 59, nuestro autor se refiere nuevamente a esta idea: "Por último, hay una tensión entre la autonomía como una noción puramente formal (donde lo que uno decide por sí mismo puede tener cualquier contenido particular) y la autonomía como una noción sustantiva (donde sólo ciertas decisiones cuentan como ejercicios de autonomía, mientras que otros cuentan como una renuncia). Así, la persona que decide hacer lo que su comunidad, o gurú, o compañeros le dicen, no cuenta como autónomo en la última concepción. La autonomía entonces parece en conflicto con los lazos emocionales con los demás, con compromisos con causas, con la autoridad, la tradición, la pericia, liderazgo, etc."
} 
AUTONOMÍA PERSONAL Y REFLEXIÓN: UN ANÁLISIS DE LAS IDEAS DE HARRY FRANKFURT Y GERALD DWORKIN

JUAN FRANCISCO IOSA

pensar, dentro del modelo dworkiniano, la idea de 'motivaciones propias' sin acudir a consideraciones de segundo orden). Debemos determinar si este elemento forma parte de un concepto plausible de autonomía.

DWORKIN rápidamente rechaza que debamos darle a la noción de independencia sustantiva el lugar que pretende y que nuestras intuiciones le ofrecen en el concepto de autonomía.

Respecto de la autonomía concebida como autenticidad más independencia sustantiva... el problema... es caracterizar cuándo una persona está renunciando a la independencia (tal vez auténticamente) y cuándo lo retiene. No puedo, sin embargo, pensar en una hipótesis que, al mismo tiempo clasifique correctamente ejemplos evidentes de no autonomía (el lacayo servil, el que se conforma a las presiones de grupo) y, sin embargo no clasifique también al hombre compasivo o leal o moral como no autónomos. Pues el hombre compasivo o leal o moral es tal que sus acciones son en cierta medida determinadas por las necesidades y urgencias de los demás. Él no es independiente o autodeterminado. Una vez más, cualquier noción de compromiso (con un amor, un objetivo, un grupo) parece ser una negación de la independencia sustantiva y por lo tanto de la autonomía. No parece haber ninguna manera de conceptualizar la independencia sustantiva que evite esta clasificación. ${ }^{32}$

DWORKIN entiende que si además de requerir que el agente elija sin interferencias su propio plan de vida exigimos independencia de pensamiento y de acción, ie, acción de acuerdo a motivaciones propias, como condición para predicar autonomía, nuestro concepto de autonomía entrará indefectiblemente en conflicto con ideas (con las prácticas que las encarnan) que consideramos moralmente justificadas (la idea de autoridad y la práctica de seguir autoridades, el amor y la lealtad, y la práctica de hacer cosas por amor o por lealtad, etc.). Por ello conviene desinflar un poco el concepto. No exijamos, nos propone, independencia sustantiva. El hombre autónomo no tiene, entonces, en el concepto que maneja DWORKIN, obligación de juzgar por sí cómo debe actuar ni de actuar sobre la base de su propio juicio. Sobre todo no está exigido de actuar sobre la base de motivaciones propias. La independencia sustantiva no forma parte del concepto dworkiniano de autonomía.

Estamos entonces en condiciones de acompañar a DWORKIN en su caracterización de la noción de autonomía personal:

La fórmula completa de la autonomía, entonces, es autenticidad más independencia procesal. Una persona es autónoma si se identifica con sus deseos, metas y valores y tal identificación no es influida en formas que hacen que al proceso de identificación de alguna manera extraño a la persona. Definir las

\footnotetext{
32 DWORKIN, G, 1976: “Autonomy and Behavior Control”, The Hastings Center Report, Vol. 6, № 1. p. 26.
} 
AUTONOMÍA PERSONAL Y REFLEXIÓN: UN ANÁLISIS DE LAS IDEAS DE HARRY FRANKFURT Y GERALD DWORKIN

JUAN FRANCISCO IOSA

condiciones de independencia procesal implica distinguir aquellas formas de influir en las facultades reflexivas y críticas de las personas que las alienan de aquellas que las promueven y mejoran. ${ }^{33}$

\subsection{Crítica}

DWORKIN pretende generar un modelo formal de autonomía que permita usar el concepto de un modo tal que nos habilite a calificar como autónomos a una amplia gama de modos de vida, o incluso cualquier plan de vida en tanto haya sido elegido por el agente sin interferencias indebidas. En este modelo formal lo que uno decide por uno mismo puede tener cualquier contenido $^{34}$. Esta elección teórica es coherente con su creencia de no hay ningún criterio objetivo para valorar los diversos planes de vida:

Una de las cosas que sabemos sobre nosotros mismos es que tenemos variados intereses e ideales, variados gustos y preferencias, variados deseos y quereres. Hay diversos planes de vida que las personas puedan tener, y en la mayoría de los casos no hay elección entre ellos en términos de algún ideal o principio de racionalidad omnicomprensivo. Lo bueno para los seres humanos es irreductiblemente múltiple y variado. ${ }^{35}$

Para evaluar la propuesta dworkiniana deberíamos poder determinar si entiende la idea de metapreferencias en términos de la concepción empírica o de la concepción normativa. Entiendo que si asume la concepción empírica Dworkin debería recortar las exigencias que postula como condiciones necesarias y suficientes para predicar autonomía. Creo que bajo esta suposición debería caracterizar el concepto meramente a través de la idea de autenticidad. La idea de independencia procesal en tanto introduce subrepticiamente consideraciones normativas, no es compatible con una concepción empírica de las metapreferencias. Sólo se puede introducir la independencia procesal como requisito si se acepta una concepción normativa de las metapreferencias. Ahora bien, si se acepta una concepción normativa de las metapreferencias, entonces parece que no se requiere identificación como condición para predicar autonomía.

Aclaremos la tesis. Estoy afirmando que, como cuestión de coherencia, si Dworkin supone una concepción empírica de las metapreferencias debería exigir sólo identificación, y no

\footnotetext{
33 DWORKIN, G, 1989: “The Concept of Autonomy", en John Christman (Ed.), The Inner Citadel. Essays on Individual Autonomy, Oxford University Press, N.Y., Oxford. p. 61.

34 DWORKIN, G, 1989: "The Concept of Autonomy", en John Christman (Ed.), The Inner Citadel. Essays on Individual Autonomy, Oxford University Press, N.Y., Oxford. p. 58.

${ }^{35}$ DWORKIN, G, 1976: “Autonomy and Behavior Control”, The Hastings Center Report, Vol. 6, № 1. p. 27.
} 
independencia procedimental, como condición para predicar autonomía. A su vez, si asume una concepción normativa de las metapreferencias debería requerir sólo independencia procesal, pero no identificación. Veamos los fundamentos de estas afirmaciones.

Comencemos por revisar la primera idea. Supongamos que debemos leer a Dworkin como afirmando una concepción empírica de las metapreferencias. Bajo esta concepción, las metapreferencias están tan causalmente determinadas como cualquier otro deseo. El sujeto puede, es cierto, en un sentido usarlas como criterio de evaluación de sus preferencias de nivel más bajo. Pero si las metapreferencias no han sido generadas por la reflexión, la idea de que las utilizamos como baremo de nuestras preferencias es nada más que una metáfora. Lo que sucede es que tenemos una actitud positiva hacia algunas de nuestras preferencias de primer nivel y una actitud negativa hacia otras.

Que tengamos o no estas actitudes es, asimismo, una cuestión de hecho. Si éste es caso, entonces el proceso de identificación con las preferencias de primer orden debería ser entendido en términos meramente causales o al menos no estar determinado por ningún juicio o evaluación respecto de qué motivaciones de primer orden es valioso tener. Ahora bien, si la identificación es meramente una actitud subjetiva entonces no tiene sentido postular restricciones procedimentales que salvaguarden nuestra capacidad de reflexión. La idea de 'interferencias indebidas' que la independencia procesal busca evitar, se vuelve ininteligible.

Veamos ahora las razones que avalan la segunda tesis sostenida arriba. Allí afirmaba que si postulamos independencia procedimental como requisito de la autonomía es porque presuponemos una concepción normativa de las metapreferencias y que bajo esta concepción debe abandonarse el requisito de la identificación.

Una concepción normativa de las metapreferencias sostiene que estas son producto de la reflexión, ie, son adoptadas libremente (siendo la libertad la capacidad de actuar por razones, la independencia del yugo causal). En tanto toda la idea de independencia procedimental está destinada a resguardar la posibilidad de juzgar libremente qué metapreferencias es deseable adoptar, parece claro que DWORKIN está comprometido con una concepción normativa de las metapreferencias. Ahora bien, si estas metapreferencias son producto de la reflexión, no podemos presuponerlas; no por lo menos al comenzar la reflexión. Nuestras metapreferencias no podrán ser el criterio de evaluación de nuestras preferencias de primer orden. Ha de haber otro criterio. Si no puede ser interno, subjetivo, si no pueden ser nuestras metapreferencias (ni tampoco otras consideraciones de segundo orden, ya que tendrían el mismo problema) este criterio ha de ser externo, objetivo. Si mis metapreferencias son fruto 
del uso de un criterio objetivo de evaluación de mis preferencias, resulta que no me hace falta acudir a ellas, a las metapreferencias, a la hora de evaluar mis preferencias de nivel más bajo. Sólo las necesitaremos como elementos capaces de motivarnos a cambiar nuestras motivaciones inferiores.

Ahora bien, la independencia procesal era una exigencia destinada a resguardar nuestra capacidad de evaluación de nuestras preferencias, no nuestra capacidad de motivarnos para modificarlas. Por ello, si existe este criterio objetivo no necesitamos entonces exigir identificación entre preferencias y metapreferencias para predicar autonomía. Un agente autónomo será aquel que reflexiona independientemente respecto de cuáles de sus preferencias ha de considerar deseables (aun si no sólo no se identifica con sus preferencias más bajas sino que además no puede motivarse para modificarlas).

Por otra parte, si la independencia procesal resguarda la posibilidad de reflexionar sobre las propias identificaciones juzgando sobre el valor de las motivaciones de primer orden, resulta difícil ver cómo se puede desechar coherentemente el requisito de independencia sustantiva. La independencia sustantiva requiere justamente que el sujeto piense por sí mismo sobre el valor de sus motivaciones de primer orden y, en una segunda instancia, que decida y actúe en virtud del resultado de su reflexión, ie, que actúe de acuerdo a motivaciones suyas, no de otros (suponiendo que se puede hacer inteligible la idea de actuar de acuerdo a motivaciones ajenas). Renuncia a su independencia sustantiva quien no juzga por sí mismo sobre sus motivaciones ni sobre cuánto peso debe darles a la hora de actuar y quien actúa meramente sobre la base de decisiones ajenas. Pero ahora vemos que si lo que resguarda la independencia procesal es la capacidad de reflexionar sobre las motivaciones de primer orden, ie, reflexionar sobre si me identificaré o no con esas motivaciones, parece, en parte al menos, resguardar lo mismo que resguarda la independencia sustantiva.

Si Dworkin quiere aferrarse a su exclusión del requisito de independencia sustantiva debería debilitarlo y afirmar que lo que la independencia sustantiva requiere es meramente que el agente actúe sobre la base del propio juicio respecto del valor de sus motivaciones de primer orden (que no requiere, en cambio, que reflexione sobre su valor, ie, sobre si se identificará o no con ellas, ya que este requisito quedaría bajo el alcance de la idea de independencia procesal). Ahora bien, si no vamos a exigir, como condición para predicar autonomía, que el agente actúe sobre la base de motivaciones que haya juzgado valiosas ¿a qué poner tanto el acento en garantizar su capacidad de juzgar al respecto? 
AUTONOMÍA PERSONAL Y REFLEXIÓN: UN ANÁLISIS DE LAS IDEAS DE HARRY FRANKFURT Y GERALD DWORKIN

JUAN FRANCISCO IOSA

Aún más, resulta difícil entender por qué, según Dworkin, el hombre moral es un caso de renuncia a la independencia sustantiva si ésta consiste en juzgar por sí respecto del valor de las propias motivaciones y en actuar de acuerdo a los propios juicios y motivaciones. El hombre moral no es aquel que no da ningún peso en sus deliberaciones a las motivaciones de los demás, vengan estas bajo la forma de necesidades, opiniones, pedidos o decisiones ajenas. El hombre autónomo (con independencia sustantiva) no es un egoísta. Por el contrario, es alguien que evalúa las motivaciones ajenas de acuerdo al peso que le acuerdan razones objetivas cuyo contenido juzga por sí. Si el caso del hombre moral no es un caso de renuncia a la independencia sustantiva, bien puede ser que DWORKIN deba incluir esta idea en su concepto de autonomía ${ }^{36}$.

Por otra parte, por supuesto que el hombre leal puede, aunque esto es contingente, ser un caso de renuncia a la autonomía (como independencia sustantiva). Pensemos en el caso de Eichmann. Pero esto no genera ningún problema. La lealtad tiene el valor que la moral le adjudica.

\subsection{Crítica de la versión empírica de la autonomía y determinación de las consecuencias de la versión normativa}

Seguidamente enumeraré algunas de las ventajas de la concepción jerárquica de la autonomía en su versión empírica. Segundo, mostraré que, a pesar de esas ventajas, tenemos buenas razones para rechazar la exigencia de identificación y la versión empírica de la autonomía personal. Respecto de la concepción normativa, tal como ya sostuve, entiendo que si

\footnotetext{
${ }^{36}$ Ahora bien, más allá de si DWORKIN hace o no bien en excluir la independencia sustantiva de su concepto de autonomía, debe reconocerse que tiene elementos a la mano para dejar sujeto a la ley y a la responsabilidad moral al agente 'autónomo' que ha renunciado a su independencia sustantiva. "Una razón de la renuencia a abandonar la independencia sustantiva es el temor de que pueda romperse el vínculo con la responsabilidad moral. Como argumenta WoLfF, si los hombres han de ser agentes responsables y asumir la responsabilidad de sus acciones, es necesario que puedan determinar lo que es correcto. Hasta aquí estamos de acuerdo. Pero no hay razón para suponer que al considerar la autonomía como autenticidad más independencia procesal los sujetos puedan evitar la responsabilidad. El hombre que hace lo que su madre le dice que haga no es más ni menos responsable de lo que hace que el hombre que piensa cada cuestión por sí mismo. Él no puede evadir su responsabilidad diciendo "ella me dijo que lo hiciera", precisamente porque, en nuestra concepción de autonomía, él reconoció su propio deseo de motivarse por los deseos de su madre y, por tanto, es responsable por esa determinación de su voluntad". DWORKIN, G, 1976: “Autonomy and Behavior Control", The Hastings Center Report, Vol. 6, № 1. p. 26. En este punto DWORKIN y WoLFF están de acuerdo: quien renuncia a juzgar por sí permanece responsable (DWORKIN se equivoca al pensar que WoLfF considera importante el juicio propio porque su renuncia acarrearía ausencia de responsabilidad moral; el mismo WolfF niega que este sea el caso. WOLFF, R. P, 1970: In Defense of Anarchism, Harper Torchbooks, N.Y. p. 14. Difieren en cuanto a si se puede decir de quien renuncia a juzgar por sí que permanece autónomo.
} 
AUTONOMÍA PERSONAL Y REFLEXIÓN: UN ANÁLISIS DE LAS IDEAS DE HARRY FRANKFURT Y GERALD DWORKIN

JUAN FRANCISCO IOSA

se la sostiene se hace necesario acudir a criterios objetivos -sustantivos o procesales- como modo de generar las metapreferencias a través de la reflexión. En este caso el modelo pierde su pretendido carácter inmanente.

Revisemos la idea de autonomía personal presuponiendo una concepción empírica de las metapreferencias.

Una ventaja de este modelo, donde la autonomía equivale a la mera exigencia de identificación entre preferencias de diverso nivel, es que permite un análisis de la autonomía en términos puramente fácticos. Prescinde de un dudoso mundo inteligible, imprescindible para cualquier análisis de la autonomía que se funde en la relación de un sujeto empírico con entidades abstractas como las normas. Asimismo, no necesita postular la idea de libertad trascendental para dar cuenta de la autonomía. Los deseos de segundo orden de la persona son tan causalmente determinados como los de primer orden. Si la autonomía es la identificación entre ambos niveles de deseos, no hace falta postular la libertad para dar cuenta de ella.

Otra ventaja, asociada a la primera, es que es un modelo puramente formal, independiente de consideraciones morales sustantivas. No hay límites respecto de qué deseos o voliciones de segundo orden valen ni tampoco los hay respecto de los de primer orden, siempre y cuando uno se pueda identificar con ellos. Por lo cual da lugar a la posibilidad de calificar como autónomos un sinnúmero de planes de vida (como el del esclavo feliz que desea tener limitadas sus opciones) que bajo concepciones sustantivas quedarían excluidos.

Por la misma razón esta concepción de autonomía no entra en contradicción conceptual con la noción de autoridad. Un agente autónomo según esta concepción puede desear sin contradicción ser el tipo de persona que desea seguir los mandatos de la autoridad. En palabras de DWORKIN:

Puede ser que haya buenas razones... para que los ciudadanos no concedan autoridad al Estado. Pero yo no creo que el argumento pueda basarse simplemente en lo que las personas autónomas pueden hacer de modo consistente con su autonomía. Si un ciudadano tiene razones para conceder tal poder, si ese es el tipo de estado en que él piensa que es bueno vivir, y ese el tipo de ciudadano que él quiere ser, entonces en mi concepción de la autonomía, permanece autónomo aun cuando conceda dicha autoridade. ${ }^{37}$

Sin embrago, y tal como sostuve, creo que este modelo no funciona. El mismo DWORKIN, en Theory and Practice of Autonomy, ha reconocido que éste es el caso tras analizar algunas de

\footnotetext{
${ }^{37}$ DWORKIN, G, 1988: Theory and Practice of Autonomy, Cambridge University Press, N.Y. p. 27-28.
} 
AUTONOMÍA PERSONAL Y REFLEXIÓN: UN ANÁLISIS DE LAS IDEAS DE HARRY FRANKFURT Y GERALD DWORKIN

JUAN FRANCISCO IOSA

las objeciones que enfrenta. Me refiero el carácter global antes que local del concepto de autonomía (la idea de identificación tiene carácter local: hoy puedo identificarme con mis deseos de primer orden y mañana no), el hecho de que hay obvias interferencias con la autonomía que no ponen en cuestión la identificación o autenticidad (puede que una persona manipulada se siga identificando con sus deseos de primer orden), la posibilidad de alterar las preferencias de segundo orden antes que las primeras para lograr identificación (así si soy envidioso y no quiero ser envidioso bien puedo alterar esta metapreferencia, dejar de querer no ser envidioso y así lograr armonía, sin embargo no parece intuitivamente que haya ganado en autonomía), la amenaza del regreso al infinito (por qué no deseos de tercer orden, de cuarto, de $\mathrm{n}$ orden?), etc. ${ }^{38}$ Por ello es que el ingreso de la exigencia de independencia procesal se impone como una condición de la plausibilidad del concepto. Y esto de un modo tal que desplaza la necesidad misma de identificación. Congruentemente, en Theory and Practice of Autonomy DWORKIN ha profundizado la vía normativa desinflando la idea de identificación:

En un ensayo anterior (Autonomy and Behaviour Control) sugerí que era una condición necesaria para ser autónomo que las identificaciones de segundo orden de una persona sean congruentes con sus motivaciones de primer orden. Esta condición, que llamé "autenticidad", era necesaria pero no suficiente para ser autónomo. Ahora creo que esto es un error. No es la identificación o la falta de identificación lo que es crucial para ser autónomo, sino la capacidad de plantear la cuestión de si voy a identificarme con o rechazar las razones por las que ahora actúo. ${ }^{39}$

La capacidad de hacerse la pregunta por si me identifico o no con las razones (deseos, hemos de suponer) por las que actúo es equivalente a asumir la capacidad de reflexionar, es decir, preguntarme si mis razones subjetivas son buenas razones desde un punto de vista no meramente subjetivo ${ }^{40}$. La autonomía personal está entonces conceptualmente ligada a la idea de reflexión. Tener capacidad de reflexionar es entonces una condición necesaria de atribución de autonomía personal. Ahora bien, si no se goza de autonomía personal sin ejercer la reflexión entonces el estado tiene el derecho y el deber tanto de obstaculizar aquellos planes de vida que tiendan a horadar nuestra capacidad de reflexión como de favorecer la elección de aquellos planes que nos vuelvan más reflexivos. En este sentido apunta el perfeccionismo liberal de Raz ${ }^{41}$.

\footnotetext{
38 DWORKIN, G, 1988: Theory and Practice of Autonomy, Cambridge University Press, N.Y. p. 15-16.

39 DWORKIN, G, 1988: Theory and Practice of Autonomy, Cambridge University Press, N.Y. p. 15.

40 Esto no equivale, es claro, a afirmar que todos deberíamos vivir de acuerdo a los mismos criterios. Por el contrario, habrá criterios que se nos aplican a nosotros dadas nuestras particulares inclinaciones, vocaciones, circunstancias, etc., y que por ello no se aplican a los demás.

${ }^{41}$ RAZ, J., 1986: The Morality of Freedom. Clarendon Press, Oxford.
} 
De acuerdo con su teoría hay claras opciones autorreferentes que son, sin embargo, pasibles de disuasión por vía de coerción. El sujeto puede ser coercitivamente disuadido de ciertas opciones autónomas si dichas opciones han de dañar su capacidad futura de decidir autónomamente. De aquí que, por ejemplo, no parezca del todo excluida la posibilidad de castigar el consumo de ciertas drogas de probado efecto incapacitante. Nada diremos aquí sobre las credenciales de dicha teoría ni sobre el modo y los límites con que justifica la coerción. Esa tarea es objeto de otro trabajo.

\section{BIBLIOGRAFÍA}

CHRISTMAN, J, 2011: “Autonomy in Moral and Political Philosophy”, The Stanford Encyclopedia of Philosophy, Edward N. Zalta (ed.), disponible on line en <http://plato.stanford.edu/archives/spr2011/entries/autonomy-moral/>

DELA MIRANDOLA, P. [1496] 1984: De la Dignidad del Hombre, Editora Nacional, Madrid.

DWORKIN, G, 1976: “Autonomy and Behavior Control”, The Hastings Center Report, Vol. 6, № 1.

DWORKIN, G, 1988: Theory and Practice of Autonomy, Cambridge University Press, N.Y.

DWORKIN, G, 1989: “The Concept of Autonomy”, en John Christman (Ed.), The Inner Citadel. Essays on Individual Autonomy, Oxford University Press, N.Y., Oxford.

FRANKFURT, H, 1989: "Freedom of the Will and the Concept of a Person", en J, CHRISTMAN (Ed.), The Inner Citadel, Essays on Individual Autonomy, Oxford University Press, Oxford, (de donde se cita). Originalmente el artículo salió en Journal of Philosophy 68, 1971.

IOSA, J, 2010a: "Concepciones de la autonomía”, en Revista Brasileira de Filosofía, Editora Revista dos Tribunais, año 59, № 234.

IOSA, J, 2011: “La Estructura del Conflicto entre Autoridad y Autonomía”, en Analisi e Diritto, Madrid, Ed. Marcial Pons, disponible on line en

<http://revistas.marcialpons.es/fichaarticulo.php?id_articulo=2187>

KAIN, P, 2004. "Self Legislation in Kant"s Moral Philosophy", Archiv für Geschichte der Philosophie, 86.

LAPORTA, F, 2007: El Imperio de la Ley, Trotta, Madrid.

NINO, C, 2007: Ética y Derechos Humanos, Astrea, Buenos Aires.

RAZ, J., 1986: The Morality of Freedom" Clarendon Press, Oxford. 
REATH, A, 1994: “Legislating the Moral Law”, Nous 28, N 4.

SIEKMANN, 2012: The Logic of Autonomy, Hart Publishing, Oxford.

SMITH, M, 1994: The Moral Problem, Blackwell Publishers, Oxford.

WOLFF, R. P, 1970: In Defense of Anarchism, Harper Torchbooks, N.Y.

WOOD, A, 2008: Kantian Ethics, Cambridge University Press, N.Y.

Artigo convidado 